\title{
The Limits of the Human Mean the Limits of Humanities
}

\author{
André Barata \\ University of Beira Interior, LabCom.IFP \\ abarata@ubi.pt
}

\begin{abstract}
This essay aims to expose an inner linkage between the crisis of the human and the crisis of the humanities in our times. Inspired by a variation of Wittgenstein's famous proposition "The limits of my language mean the limits of my world", it is claimed that the humanities refer to the human through a common and singularising experience of limits of the human. However, arguably, it is precisely this experience of limits that is threatened since moder-

nity has become a process of progressively literalising reality, eliminating ambivalences, and trivialising meaning, with psychoanalytical and political consequences that we can see, for instance, in extreme ways, in today's fundamentalist actions. Given these crisis aspects, I argue that the post-human experience provided by sci-fi is a rather important source of resistance for the human and the humanities.
\end{abstract}

Keywords: human; post-human; humanities; limit experience; modernity; crisis.

\section{Limits and limits}

$\mathrm{T}$

HERE are many ways in which the limits of the human can be investigated, many of them related to the time we live in. But there is one in which those limits of the human mean the limits of the humanities and, especially, the limits of philosophy, as the radical inquiry into humanities. This is quite a timely question to bring to discussion. I will try to shed light on how the contemporary human condition is compressed within its very own limits and how philosophy's uneasiness nowadays is a symptom of a new form of discontent in culture and civilisation. That pressure on the limits of the human is exerted in at least two only apparently divergent ways: oppressing the human condition against limits as much as liberating the human condition of any distinctive limit. One way or another, the malaise seen today is an erosion of humanity, as the final, often announced consequence of the modern history of eliminating ambivalence in the human experience. From this perspective, the proposal for rethinking the humanities must be a proposal on the experience of limits, old and new experiences of limits of the human, old and new reflections on limits of the human experience. It is in experiencing the limits of the human - that the humanities offer us - that humankind proves its limits and a meaningful singular common existence.

A Revista Estudos em Comunicação é financiada por Fundos FEDER através do Programa Operacional Factores de Competitividade - COMPETE e por Fundos Nacionais através da FCT - Fundação para a Ciência e a Tecnologia no âmbito do projeto Comunicação, Filosofia e Humanidades (LabCom.IFP) UID/CCI/00661/2013.

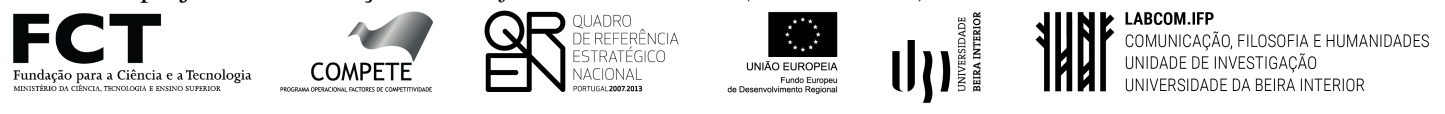




\section{The end of limits as the end of limitations}

The limits of the human can be conceived in two senses - one is much more obvious, although we tend to perceive it inadequately. The other is much more crucial, though much less obvious. Due to this asymmetry, it may often happen that the brightness of the obvious blinds us to the crucial issue that we should see. And maybe we should consider that this shining effect is not just an incidental circumstance, but rather a constructed one, even if it is unintentional. The shining sense of the limits of the human is the one we usually refer to when thinking about the accelerated processes of modifications taking place in our bodies, our minds, and our physical and mental capacities due to technology. We are going through a vertiginous perception of the dissolution of the limits of the human in a sense close to a presumed end of limitations. I do not disagree, although that acceleration is still more anticipation than fact. Enough to recognise that we have strong reasons to meditate on that dissolution of limits and on the extension of human frontiers, foreseeably in a future not that far from us today, moved to horizons that are quite foreign to the natural design we are born with. And it is an interesting exercise to conceive what could be the limit of this dissolution and extension of limits. For instance, sooner or later, we will be able to free ourselves of mortality by turning off the ageing genes, which have already been identified. Another example is the extension of memory implanted in our brains, as well as computing processors able to compute for us, giving us reasoning capacities unparalleled in the past. A final example is the technological project of freeing ourselves from our bodies, which might be achieved assuming that personal identities can function in different matters just like software runs in different hardware, or, even assuming the impossibility of disconnecting personal identity from a singular body, the former could nonetheless live in an artificial, virtual world. Without a body, or at least without a specific, intimate body, without death, or at least without the certainty of its arrival, we could reasonably expect the more basic conditions of existence - our place in time and space - are being or will soon be transformed. Of course, changing the very basic conditions of human existence challenges what human beings are or can be. But, more fundamentally, what is challenged is our expectation about what human beings should or should not be, according to preconceived views of the human. In fact, limits can mean lots of different things. One of them is risk, threat, as when someone blames another for going beyond acceptable limits. This is a challenge that should matter to us. To put it more clearly: why should humans' humanity have no trace of technology? Who is the human being in $2001-A$ Space Odyssey: the primate extending his arm with a wooden stick to be able to hit other unarmed primates, or these poor victims of a strange technology? From a certain perspective, haven't humans been post-humans since the beginning? Their ability to make plans that transcend them, their being responsible for choices and acts out there in the world, their making something they are recognised as creators of, the mere fact of possessing a language that is used to speak and say things out loud; aren't all these skills accepted as distinctive of humanity? And, at the same time, don't all these manifestations of humanity imply going far beyond humans' natural limits? If we agree on this point, we would also agree that there is a certain illusion in considering post-human as the result of natural born limits being removed or overcome. That is basically the history of humankind and that is why Donna Haraway is right when she claims in A Cyborg Manifesto (1983) - which is in itself a metaphor - that there is a need 
to dissolve distinctions, and, before that, to dissolve a perspective based on dissolving distinctions. So the difference is elsewhere, radically elsewhere, but still involves a notion of limits. That, at least, is the hypothesis I would like to explore.

Stanislav Lem's Solaris (1961) and Tarkovski's extraordinary adaptation (1972) underlined the same illusion about a conception of limits to be overcome as if they were boundaries. In the novel, the boundaries are not directly related to the limits of the human being. However, the limits at stake in it are the limits of the human world. Extending them means nothing but making mirrors of ourselves.

"We don't want to conquer the cosmos, we simply want to extend the boundaries of Earth to the frontiers of the cosmos. For us, such and such a planet is as arid as the Sahara, another as frozen as the North Pole, yet another as lush as the Amazon basin. We are humanitarian and chivalrous; we don't want so enslave other races, we simply want to bequeath them our values and take over their heritage in exchange. We think of ourselves as the Knights of the Holy Contact. This is another lie. We are only seeking Man. We have no need of other worlds. We need mirrors. We don't know what to do with other worlds. A single world, our own, suffices us; but we can't accept it for what it is." (Lem, 1961)

This movement of the human towards its own extension fails in the crucial aspect of others' otherness, as Emmanuel Levinas made clear. The other is not simply an alter ego, another "ego" like my own "ego", since, after all, my own is the only "ego" I know directly (Levinas, 1961). The other is, in its otherness, neither similar to nor different from me. The otherness of the other is not related to cognitive aspects, but to relational aspects instead. The other is the one with whom I have a relationship as if he were an infinite transcendence that I am not able to place into any kind of category. My relation with the other, if genuine, is therefore a relation without a frame.

What could better describe otherness than the limits of human?

\section{Why do humanities matter here?}

One could ask what humanities have to do with all these concerns about the human. I believe they matter because they give us another meaning for the word "limits" in the context of a reflection on human limits; limits not in the sense of limitations, or boundaries, but in the sense of limitexperiences, common, universally recognised experiences and uncommon, singularly intensified experiences taken to the limit. I shall give only one example, taken from the tradition of ancient tragedies, taken from the thousands that could easily be evoked to illustrate this point. I have in mind the case of a limit-experience of revenge in Euripides' Medea - a woman who kills her own sons in order to deny any possible comfort to the person she hates boundlessly, her sons' father. It is hard to conceive a more radical hatred and a more radical revenge than those Medea has.

These kinds of limit experiences are related to Lacan's psychoanalytical theory and the experience of "jouissance" investigated in "The Ethics of Psychoanalysis" (1959-60). For Lacan, these experiences, in limit situations, go far beyond the pleasure principle, involving dimensions of suffering in states of intense energy release. 
I do not want to assume that humanities are, in essence, or should be, as a normative claim, fields of experience and interrogation of human limits, in this sense of "limits" that infinitely intensify the consciousness of being human. I just want to assume that they have been so in many of their most remarkable works. I have no problem admitting that perhaps not all great works have approached the limit of human experience. It is not important to my point of view to comfort us with a definition of humanities as strict as stating that they are always or should always be related to the issue of human limits. In fact, I hold a rather modest assertion about humanities - that they have been, in many of their most memorable realisations, deeply affected by those human limit experiences. And I have a less modest second claim. Limits in this sense are not limits conceived as borders or limitations, as we have seen. Quite the opposite, these limits are at the core of human condition. They are exemplary, enlightening far beyond their circumstances. And they are relevantly practised, studied and reflected within the humanities.

But why does it matter so much to drive human experience to infinitely intensified limitexperiences? How can experiences as unlikely as Medea's hatred for Jason say so much to so many of us, and for more than two millennia? In more abstract and summarised terms: why can singularities express something universal? In fact, here, we are close to the Sartrean motif of a "singular universal" (Sartre, 1960). Both the radicalness in the choices we make and our taking experiences to their limits are singularities that block any attempt to assign relative values. The very fact of something being singular means it has no way of being made conditional in its uniqueness. And without relativity framing, singularities apply to all cases.

While it was important to find other reasons why we humans should treat each other not only as means, but at the same time as ends - recalling the famous second formulation of the Kantian categorical imperative - I think we find here the starting point for a whole reflection feeding ethical formalism with distinctive human experience.

Singularities can be shared but are not interchangeable in bargaining terms, as happens in situations of trade-offs between values we transact or negotiate. Here, we could make a comparison with arithmetic operations with infinite quantities. In infinite quantities, double and half are the same. One thousand times the infinite is no more than one thousandth of the infinite. The truth is that there is no "more" or "less" in sums, subtractions, multiplications and divisions in the infinite. The truth, to complete this comparison, is that there is no possible arithmetic of the singular. And that is an important reason to think of humanities as a Kantian kingdom of ends, but certainly not one defined as a "union of different rational beings under common laws".

Preventing the dehumanisation of the human condition relies on this passage to the limit of human experiences, through a common experience practised, studied and, above all, the subject of concern within humanities. Therefore, what the human is depends less on what human beings really are than on what the humanities are and can account for. Without humanities, our humanity rarefies. Turning again to the previously mentioned first meaning of "limits" as limitation, I believe I can say that, in that sense, the limits of the human are the limits of humanities and no others. And the other way round, precisely because of the sense of exemplary limits, the limits of humanities are what define the limits of the human. 


\section{Blade runner blues}

It is worth noting that this way of conceiving the human as the limit-experience of humanities does not have to be the hallmark of the material human beings we actually are. The notion of human depends less on our biology or our natural born conditions than on the humanities' attention to the human experience. In reality, it is humanities that look after human beings' humanity, in a caring, all-encompassing, intimate and not always easy relationship.

Following these arguments, there is another example I would like to discuss, because all the dimensions of human limits mentioned above are at stake in it - Ridley Scott's movie Blade Runner, an adaptation of the Philip K. Dick science fiction novel Do Androids Dream of Electric Sheep? In this iconic movie, the intensification of the human is performed through the amplification of the non-human. The crucial question is why aren't they human? That intensification of limits, however, betrays the intention to keep them out of the circle of humanity. The limits are the same, but they are seen from the outside, from a backlighting perspective, that emphasises edges and contours. Roy, Rachel and Rick carry out Hegel's dialectics of acknowledgement, no longer between the master and his slave, but instead between the human and his post-human simile. In fact, there is an intense post-human nostalgia. For Roy, there is a dialectical need for Ricks' recognition, despite the a priori certainty of failure; Rick falling in love with Rachel will also fail. Nostalgia is the pain of loss intensely grasped in the soundtrack that Vangelis composed for the movie: blues, with a groove rhythm.

In short, as much as humans have been post-human since the beginning, those coming from a post-human reality are, actually, still pre-post-human. Or, in a word: simply human. In fact, the singular universal Sartrean motif is perfectly embedded in the words of Rick Deckard, uttered in voice-over right after Roy's death.

"I don't know why he saved my life. Maybe in those last moments, he loved life more than he ever had before. Not just his life. Anybody's life. My life. All he'd wanted were the same answers the rest of us want. Where do I come from? Where am I going? How long have I got? All I could do was sit there and watch him die."

Finally, from this point of view that intensely questions the limits of the human from outside, we can find a deep resonance between Roy and Rachel's suffering in Ridley Scott's Blade Runner and the same existential pain in Solaris's Hari. Her words could not be more acute:

Yes. Maybe. But I...

I am becoming a human being.

I can feel just as deeply as you.

All three die intensifying the consciousness of the human at the very limits of human.

To complete this section, we must return to Freud's 1919 essay Das Unheimlich. For Freud, the uncanny experience of familiar strangeness claims that in the most familiar experiences we can simultaneously have an unfamiliar experience. The psychoanalyst describes Unheimlich as "that class of the frightening which leads back to what is known of old and long familiar". An impressive example is the Unheimlich that male patients often declare to feel about female genitals. According 
to Freud, that feeling of uncanny is related to an old familiarity: the memory of their own mothers' uterus, as if, when making love with a woman, they were sensing where they had been before. Reflecting on this "uncanniness", Freud was therefore refusing any idea of translating the familiar and the unfamiliar as experiences of the old and the new, respectively. On the contrary, the fact Freud wanted to point out is that novelty can be not at all disquieting and that the familiar, in turn, can be quite disquieting. Freud underlines intrinsically ambiguous or ambivalent status of the uncanny experience, which merges familiar and unfamiliar into a single feeling - "Thus Heimlich is a word the meaning of which develops towards an ambivalence, until it finally coincides wits its opposite, unheimlich."

However, the most interesting aspect in this one of Freud's essays is still to come. And it concerns not the feeling of uncanny itself but the conditions that most easily induce such feelings. And, in this regard, Freud quotes Ernst Anton Jentsch, author of "On the Psychology of Uncanny" ("Zur Psychologie des Unheimlichen"), an article from 1906. In the article, the German psychiatrist, who would die the year Freud publish this quotation - materialises the conditions of uncanny he had in mind very clearly:

"In telling a story, one of the most successful devices for easily creating uncanny effects is to leave the reader in uncertainty whether a particular figure in the story is a human being or an automaton; and to do it in such a way that his attention is not directly focused upon his uncertainty, so that he may not be urged to go into the matter and clear it up immediately, since that, as we have said, would quickly dissipate the peculiar emotional effect of the thing. Hoffmann has repeatedly employed this psychological artifice with success in his fantastic narratives." (Jentsch, 1906)

While Jentsch mentions Ernst Theodor Hoffman's fantasy writer as an example of someone who made successful and repeated use of this "psychological artifice", Freud goes further, developing an analysis of one particular short story by the Konisberg writer - Der Sandmann (1816). Surprisingly, the example involves an illusion concerning the human appearance of a doll automaton, a fact that brings us immediately back to the universe of references in which we started this reflection on the human.

Moreover, the intimate relation between the limits of the human and the meaning of the human demonstrates a robust parallel with the ambivalent feeling of uncanniness that brings together familiarity and its opposite. In fact, it is exactly this common ambivalence that is actually behind the possibility of discovering what is most human in the human in the human's furthest limits.

\section{The times we live in}

The meaning of human that I have been suggesting is a common experience of singularities that we take as exemplary in our self-recognition processes. But, in this proposal, which is far from being a definition, the times we live in seem to barely tolerate the human. Our times are ruled by a hegemonic law that prescribes a universal equalisation in order to make everything the subject of exchanges and movement in a flawless, unstoppable, absolute system of atomised, equal 
individuals. These two aspects must be considered carefully: everything is equalised, everything is unstoppable.

The equalisation movement - which has nothing to do with equalitarian ends - attempts to make things exist in an identical, literal mode, closest to the flat surface of reality. Making people as literal as things is actually a great metaphor for times we live in - times in which everything is levelled, overturning all forms of figuration, metaphor, fiction that would form wrinkles and twists on the literal surface of the real. Like a wave tearing down all the sand castles that make the human singular. The real without an unreal orography is not human. We could imaginatively conceive this unreal orography as the true subject of humanities.

The acceleration of social time is not only a consequence of technological progress. It is also a global device of immersion in an unstoppable and overwhelming movement, in which we are so immersed in ready-made answers that our ability to ask questions drowns. Any questions that go beyond the resolution of difficulties are obstacles that threaten the efficiency of movement and all the benefits that come with it. That is why the malaise in the culture today produces the symptom of a deep malaise in philosophy.

Faced with these two aspects, the political meaning of today's social claims such as the basic right to placemaking in space or time becomes more evident. For instance, the right to occupy spaces and establish communities, or the right to fill time entirely with projects that await a singularity yet to arrive. Fundamentally, however, what these signs mean is that a counter hegemonic tendency must stem from humanities to overcome the malaise of the contemporary human. Those humanities shape an unreal orography of singularities and also stop the flow of answers with a boost in interrogation. To think is, ultimately, to interrogate, to co-create concepts and meanings and to care; or, in other words, to stop, to feel a meaningful surface and make it gain shape, like a potter working the clay.

\section{The future of humanities, the future of human}

Stopping is not easy these days of accelerated time, as we have seen. Humanities, and philosophy in particular, are challenged to resist and overcome the malaise of culture nowadays, since they give meaning to the limits of the human. But for that, humanities first have to overcome their own signs of crisis, decline, twilight, to overcome the attempts to drive them into literalisation processes that, ultimately, move toward an annihilation of the humanities' subject. In fact, humanities observe a landscape of which they are always also part. This is particularly relevant in philosophy. Faced with tendencies that push it to become a technology of philosophical commentary, an analytical dissection of arguments, or a productive device for answers and flowing progress, philosophy has to come back to its original condition of radical inquiry, so radical that it does not accept any inquiry without questioning its own conditions of inquiring. This is why the question "What is philosophy?" is an intrinsically philosophical question. And this means at least two things. Firstly, that the foundation of philosophy is a question that comes from within philosophy. And, secondly, the permanence of the question "What is philosophy?" is, after all, the guarantee that philosophy will not shift away from the restless condition that actually connects its authors and its readers with the real. Therefore, philosophy means an activity and not just a set of theories, arguments 
and ideas, accumulated over human history. It means a practice of unconditioned interrogation that focuses on any part of reality.

Nowadays, there is a social perception that humanities, and philosophy in particular, are superfluous. I do not believe that superfluous character should be overcome. Doing such a thing would mean selling its soul. Philosophy for instance has not allowed itself to be conditioned by any criteria of usefulness since the very beginning. To do otherwise would be to compromise its radicalness. But, at the same time, that refusal is precisely what guarantees that philosophy is not useless. Its kind of interrogation without constraints does not allow for the unquestionable. That is something that is full of useful consequences. Simply put, these considerations only matter if philosophy does not drive itself into an elitist, conservative domain of erudition with rigid limits. If a hegemonic tendency attempts to exclude philosophy as superfluous and unproductive, it is no less true that the strictness of those limits imposed by their practitioners exemplifies the very same hegemony by other means, despite what may look like resistance against hegemony. And this is also very true for humanities in general.

What should be done? First: stop, go back to the beginning, and rephrase things. The limits of the human are the limits of humanities. For the human truly has no other limits than those that humanities create and maintain through culture, no matter how changed our future world may be. Human is not a natural concept, but a certain notion of limit that has no a priori limits. Secondly, there is a consequence to be pointed out here: the fate of the human condition is not oblivious to the fate of humanities. Humanities will not save the human and vice-versa. The point is another one: they are undergoing the same crisis. The decline in the number of students so often mentioned with concern in humanities' academic departments, the defensive elitism of many of those departments, the social perception, often politically accusing (in rather consequential ways) humanities of being unproductive, the very idea that humanities should or must submit to scientific seriousness and productive rules, all these are aspects of the same annihilation we witness when we approach the contemporary condition of the human. The compression of opportunities to make places, both in space and in time (which is in fact a compression of singular possibilities), together with universal equalisation, promotes the hegemony of means over ends that we are currently experiencing.

But, after weighing all these facts, what can humanities possibly do for the human's sake and their own? It is obvious that humanities need to recover their lost centrality. And this must be done in more than one way. Against all epistemological efforts to make them sciences, as they are no such thing. Of course we can apply scientific methods to its subject, but what bizarre kind of true facts and laws would be read in an unreal orography. Humanities' purpose is, ultimately, if there is an identifiable goal, related to meaning and not to truth and laws. This does not mean any revulsion directed towards science. On the contrary, it means there is a need to establish a different relationship between science and humanities - instead of submitting humanities to a scientific frame, promoting mutual enlightenment as happens in research domains like neurophenomenology or promoting technological contributions as means to creating new points of view on human experiences, as happens in projects like those known as digital humanities.

Decisively, however, the centrality of humanities depends on finding paths we can walk along and rivers we can navigate through the orography that goes beyond academia. It is crucial to find 
passages from more classical academic humanities to non-academic humanities, especially those that are more directly exposed to the challenges of the limits of the human. Cinema, literature of anticipation, videogames, virtual life, and cyberculture are emphatically exposed to these limits and, at the same time, are no less disposed to inquiries on the human experience than older humanities. This also means that humanities should flow among each other without so many status concerns involved. In truth, this agenda is not significantly different from the one Donna Haraway was proposing 33 years ago with cyborg politics - "Cyborg politics is the struggle for language and the struggle against perfect communication, against the one code that translates all meaning perfectly (...)" (Haraway, 1983, p. 312). Resisting against thought based on boundaries, distinctions, identities, essences; replacing those limits of the individual with a different notion of limits, one that universalises. We may need a revolution of limits.

These challenges are timely and too urgent to be avoided or ignored. What I have called a literalisation process is a sort of end of the modern ages, but through the paradoxical excessive success of those ages. Modernity was always a project to rationally replace ambivalences with clear, distinct ideas, as Zygmunt Bauman underlined. But that process became a kind of idolatry. We have been witnessing that literalisation process in many contexts for a long time, but one of the most extreme manifestations of this late-ultra-modern idolatry is the phenomenon of fundamentalism. If we think about it, what is Islamic fundamentalism but Islamism without the corresponding humanities? After all, the problem is not fundamentally a problem of lack of science, nor of excess religion, but a problem of literalisation of the real, the religion, and even the sciences in their most technological developments.

Being human is not equivalent to the human being. A world of human beings does not necessarily mean a human world. Nor is the opposite true: a human world does not require any human beings. Human does not have to mean clinging to an existent human or any other existent being in particular. What must be at stake about the human is an existence, not an existent being. Even if it were a God. The last words of Cyborg Manifesto could not be more enlightening about this conception of human: "Though both are bound in the spiral dance, I would rather be a cyborg than a goddess". And Roy, close to the end of Blade Runner, kills his own creator. Surviving the limits and their revolutions means keeping things human, just human. And for that, no less than in the 1980s, it makes sense today to say: Let's cyborg the humanities!

\section{New humanism}

Could this be the content of a new humanism? I have not used the word "humanism" until now. It is a word that has been too abused to be used without consequences to which I do not subscribe. But, still, yes it could, provided that we do not forget the relevant criticism developed, for instance, by Lyotard and many others who are usually included in an anti-humanist tendency. It is not acceptable to return to an essentialist, exclusivist conception of the human, which was, quite ironically, always the basis for the exclusion of others (and first of all other human beings). It is not acceptable to soften that conception and, at the same time, promote what is basically an extension of limits, an augmentation of capacities, in the trail of limitless power that once again has human beings as its prime target. Even an ontological perspective such as the one Sartre sustained in 
"Existentialism is a humanism" is not divorced enough from the ambitions to demarcate a certain existent thing, ourselves, once again, as ontologically unique. A new humanist perspective must be much more radically disposed to lose any privileged reference to human beings. Being human requires the exercise of not being a human being, moving our expectations of a type of existent thing to a type of existence. If existence is a way of being characterised by being outside the frontiers, then being human is being out there. A new humanist perspective must be based not on any particular existent things, but on a singular universal existence. For the sake not of mankind, but of humankind!

\section{Modernity as a project of the elimination of ambivalence}

Zygmunt Bauman has proposed a reading of modernity as a project to bring about an increasingly rational order to a disordered world: the announced 'causa finalis' of the modern state was a rationally planned society. He also notes that the created order is always confronted with an irremovable remainder that disturbs it. In theory, to create order is to create, as its by-product, ambivalence, so the project of modernity has ended up historically culminating in a war on ambivalence - establishing and maintaining order means, first and foremost, purging ambivalence. And politically this has meant to segregate, to deport and, ultimately, to terminate the alien (Bauman, 1993). The limit situation of this elimination of ambivalence was the Holocaust. But since then, the same broad tendency upsurges in many different manifestations. And, today, the exclusion of the ambivalent still stems from the very premises of modern rationality. Resisting such a tendency involves transforming those premises. What is at stake is, as Bauman says, to "learn to live with polysemy with the ambivalence and the endless possibilities of an undetermined world."

But how can that be done in a capitalist context, in which the type of domination exercised requires the most explicit and transparent rationality of self-interest and the amplification thereof? In fact, there is a completely exposed sincerity in self-interest and the steps it takes over time, which is not reconcilable with the existence of obscure or ambivalent areas. The self-evidence of rational choice procedures, credit and debts records, utility curves, the complete identification of exchange value operations, the exhaustive memory of debt and related interest: all these aspects clearly show that capitalism and its arenas need to function exclusively on a conscious plane.

In psychoanalytic terms, the description of this type of domination must be provided as completely as possible in each of our conscious egos. And it is following this dominance of the ego that we find the basis for the emergence of the abstract outline of a homo economicus, which became a sort of universal key for the rational understanding of all human action, be it in economic behaviour or in moral behaviour. In this context, although relatively commonplace, it is still important to note how the Freudian economic model suits the outline of homo economicus. ${ }^{1}$

Freud was able to capture this spiritual condition of the era when he lived and, at the same time, he was also able to reveal the illusion of an alleged autonomy of human action which is,

1. For instance Birken, 1999: who has argued in a paper ("Freud's "Economic Hypothesis": From Homo Oeconomicus to Homo Sexualis") that "Freud's use of the term "economic" implied that his new psychology was somehow analogous to the earlier science of political economy, precisely because he had extended to the private the quantitative approach already employed to analyse the public sphere." (American Imago, vol. 56, n. 4 (1999): 311-330. 
after all, much more apparent than real. The censorship effect and repression processes concealed an unconscious life, sentenced to express itself only through symbolic means. So in an era marked by the triumph of the bourgeois, those phenomena could only have as important an expression as that which Freud gave them.

Moreover, even from a historical point of view, the very idea of shifting towards the centrality of the ego is sharply confirmed. In fact, the emergence of capitalism with the shift from the old regime to the hegemonic regime of the bourgeoisie was accompanied by a revolution against domination of the superego through theological and patronising values. The emergence of the emancipatory ideals of socialism and, before that, of the Enlightenment itself, is surely common to the very establishment of capitalism. Equality and natural rationality demanded that the ego took over its centrality in order to lead life with autonomy; however, this assertion was delusive. At least in one of its major aspects, this was modernity.

However, modernity has failed at least three times. Firstly, in the nineteenth century, the intensification of man's exploitation by man massively dissociated mankind from humankind. Secondly, in the twentieth century, human reason left to its own delirium collapsed into German and Soviet totalitarianism. Finally, in the twenty-first century, it is the humble reason, known as modest and reasonable, that collapses. These were three failures of modernity, or the three failures of modernity driving the idea of autonomy. It has failed with the autonomy of instrumental reason, which unfortunately served exploitation so well. It has failed with the autonomy of the total reason that sucked up all the uniqueness of life to the greatest degree of inhumanity, in a totalitarian annihilation of existence. Finally, it has failed with the autonomy of the single person who finds him/herself today reduced to the status of a fragile helpless castaway, abandoned in ultra-individuality, threatened by powers that transcend common sense, reasonableness, i.e. the very cement of the ideals of greater social justice and equal opportunities, or, at least, some bonds of community.

The bourgeois man is indeed a greatly self-contained human being, because his success relies entirely on the self-restraint he demands from himself, and above all on the self-restraint he requires from the others. In other words, being austere is a predictable demand within the bourgeois framework. We know that austerity policies have become ideologically commonplace in the present decade, but the fact is that they are not that new. They have a history that, for example, Sartre reported in his Critique on nineteenth-century French industrial society.

This ultra-individualised condition of modern individuals has gradually become unbearable. It involves excessive strain on the walls surrounding ego, sustaining individuality. Too individualised, isolated, self-sustained, and absolutely dependent on one's own choices, the prevalence of the ego's autonomy fails and collapses. Somehow, Sartre's existentialism was right: it was an expression of modernity, both in the individualist affirmation of modern existence as well as in its condemnation to unavoidable failure. The claim of absolute, solitary responsibility for one's own choice is as modern as the unbearable closeness that condemns each consciousness to face others as enemies. In both the senses of extreme individual autonomy and a lack of success, existentialism is, above all, a continuation of Kantism and Lutheranism. It is certainly more than that. But it is also that. 


\section{Signs of our times I: from a politics of ego to a politics of id}

The walls built throughout modernity are now crumbling due to a pressure that outstrips all acceptable limits. In their collapse, symbolic processes are worn down and the id becomes exposed matter, with no other form of expression than revealing itself as a naked life drive, where literalising succeeds symbolisation.

What politics discovers today is this truly traumatic shift of the motivational focus from autonomy of the ego to heteronomy of the id and its drives. In recent years, this domain shift has been becoming violent, even terribly violent.

The superego inhibitory processes have long since become politically marginal, and have been gradually replaced by surveillance devices designed from the point of view of consciousness and rationality. The political correctness is vigilant like totalitarianism is vigilant, and is adverse to the persistence of any equivocal, ambivalent, metaphorical sense, or any another shadow of the symbolic. And that is the history of modernity.

However, these surveillance devices are doomed to fail because they self-contradict the very premises that engender them. Autonomy is replaced by domination, if not by pure violence. In this context, it must be noted that there is a malaise that is no longer exactly the malaise that Freud has signalled in his time. But perhaps there are some compelling reasons to believe that this new form of malaise might be more Freudian than Freud's own. In fact, today, the id erupts in community life ambitiously claiming authenticity: against relativism, against political correctness, even against the West. At last, free from censorship, the id erupts without elaboration, basing the path for political legitimation on the most extreme literalness. This is pretty much the case of "neocons" appealing to true American values, as well as European nationalisms appealing to identity values, and also the Islamic State's project for an absolute literalisation of Islamism, even if it includes only selected parts of it. At least from this perspective, Islamic State actually extends modernity to its paroxysm, far from the return to the medieval of which it is accused.

In an attempt to understand the Islamic State as a consequence of the malaise of modernity in which we somehow all find ourselves, at least two important aspects must be underlined. Firstly, it is crucial to note how the political action adopted by Islamic State is marked by the most extreme literalness and, at the same time, the content of that political action is quite prominently related to Eros and Thanatos, the two drives Freud interconnected in Civilisation and its Discontents (Unbehagen in der Kultur).

On the one hand, there is an extreme repression exercised over all aspects of the life drive (Eros). Indeed, the Islamic State do everything conceivable to repress any opportunity to achieve pleasure, prohibiting any stimuli that could become a pleasure experience. Timbuktu (2014), a movie directed by Abderrahmane Sissako, is a poetic but painful illustration of this meticulous repression of Eros. Islamic State, or one of its trans-Saharan derivatives, reaches and dominates Timbuktu, the historical city in Mali, where trans-Saharan trade routes met a long time ago. Scenes of suddenly transformed everyday life follow in the film, which has a strong documentary feel: a woman punished for leaving her hands intentionally uncovered, refusing to wear gloves because she needed to touch the fish she was selling with her fingertips, although she had already agreed to have her head and face completely covered; a group of young people of both sexes punished 
because they were caught singing and playing music at one member of the group's home; another group of young men, playing football, but just imagining the ball they would play with if they were actually allowed to. These are not the signs of a clash between civilisations. In this culture, people also sang, danced and erotically coloured their everyday lives. More precisely, these are signs and quite specific consequences of a clash with the deep malaise of common civilisation. The repression of the Eros that Freud identified 85 years ago as a civilising principle is confirmed here and taken to the limits of inhumanity that humanity can bear.

This extreme repression of Eros carried out by the Islamic State is joined by an extreme release of Thanatos, which is too obvious to be denied in these exact terms. This fundamentalist appropriation of Thanatos can be seen in the unstoppable will to destroy any acquired civilisation, exploding all the monuments that can be reached, namely those that are so singular that their disappearance is a definitive and irreversible loss of culture's history. The extreme release of Thanatos can also be seen in the limitless will to murder and cause the most painful mortification for others, seen on the most global scale possible. Examples of this include what happened to the Jordan aircraft pilot, burnt alive in a metal cage, and the tens or hundreds of soldiers beheaded using short knives to draw out their pain.

Exemplifying so the Freudian hypothesis so directly, these two types of violence - a no-exit repression of Eros and a non-stop destruction of civilisation - entirely prove this hypothesis' relevance. Moreover, these two forms of violence are performed using the most literal means conceivable. In fact, they are performed beyond any possible conceivable limit that could keep one apart from the other. There is as much destroying Thanatos in Eros' repression as libidinal joy in Thanatos' explosions. This is the impossible limit that betrays attempts to carry out a complete literalisation of human inhuman experience. The truth is that it would be impossible to annihilate ambivalence. Human hands, no matter how inhumanly they act, can only go so far.

Having led us for centuries from the stage of superego's dominance to a stage of increasing dominance of the ego over the other elements of Freudian thought, this evolution in modernity I have been describing moved in another direction. No longer towards the autonomy of the ego and its rationality, nor towards superego again. The times we are living in nowadays are continuing modernity in the sense that they lead us to continue the same descent as before, by the Freudian parts of the psyche, but now towards an instinctual stage based on the id itself.

The relegation of autonomy, like the political category that parallels the ego's dominance, does not encourage a return to moral inhibitions organised around the superego. Instead of a return, this relegation takes advantage of the openness of a fragile ego to release the instinctual forces that inhabit the id in an unstoppable cycle of violence powered either by repression forces or by release processes. This cycle of violence is driven to a devastating collapse that will eventually happen unless some greater external force intervenes and stops the instinctive struggle cycle. The fate of the Islamic State, like an individual annihilating his/her superego and ego structures, can only be destruction without limits, in which there is no contention action from the point of view of a "reality principle".

Religion in its fundamentalist configuration does not symbolise a parental protection that attempts to respond to the experience of helplessness or to console us before a world that does not seem to have been made to satisfy the pleasure principle. This Freudian representation of religion 
- well explained in Civilisation and its Discontents - takes the form of an instance of the superego, but based on the fragile limits of which the ego is aware. And it is indeed as benign as Feuerbach's idea of God as the limitless projection of what is recognised and appreciated in a limited way in humans - knowledge as omniscience, power as omnipotence, good as a supreme good.

However, as we have seen, the fundamentalist configuration of religion does not intend to originate a superego projection to overcome the limits of the Ego, expanding them or at least offering a feeling of consolation. On the contrary, the fundamentalist approach intends to abolish the ego. And the reason for such an attitude is no mystery. That abolition is required to free the id, which is expected, in turn, to be the source of limitless and invincible power, overcoming the fragile human condition. According to the interpretation I have in mind, the fundamentalist response demands a return to radical authenticity found in an id that must be set free from the chains of symbolisation, censorship and, ultimately, the tricky plots of the ego and autonomy. For these reasons, fundamentalism, at least as we have been witnessing it in recent times, is still a response to the fragile condition of the ego. Simply put, it eliminates and replaces the ego, rather than extending or protecting it.

\section{Signs of our times II: Literalisation, again, as a form of the spread of the banal}

I have suggested an erosion of the real, which is left without relief or other orography beyond pure flatness. Without symbolic meaning and ambiguity, our reality is being reduced to literalness. Actually, that was the condition necessary for satisfying the ambition of universal interchangeableness. In this context, it is useful to recall the analysis Sami-Ali did long ago. In The Banal (1980, 2002), the Egyptian psychoanalyst describes a replacement of the imaginary with the real. And he also maintains that this replacement is accomplished precisely through an increasing prevalence of the banal over other forms of familiarity.

But how does the banal proceed? What is distinctive in processes that spread the banal? SamiAli states that the banal inhibits the projection without which there is no imaginary position. But how does that happen? According to the psychoanalyst, in its origins, the banal breaks down the intimate relationship between the familiar and the strange contained in the Unheimliche experience, as already mentioned. The banal is therefore the familiar, but not all the familiar - the banal splits the familiar because it is only the familiar that, once completely consigned to its familiarity, no longer has anything to do with the strange.

This hegemony of familiarity and the familiar not only excludes Unheimliche, but also denies subjectivity. In these terms, Sami-Ali connects the pathology of the banal with the pathology of social conformism, in which there is one relevant aspect to emphasise: the devaluation of everything that is not real. The familiar can become banal precisely when it can no longer be uncanny and disquieting. In other words, we find in Sami-Ali analysis the same erosion effect of the unreal part of reality.

What constitutes a problem in the banal is that the real, which is simultaneously rational and technical, increasingly tends to take the place of the imaginary. The imaginary joins projection through a fundamental link so that, through the banal, the whole issue 
of projection is again approached from the negative aspect of an absence of projection:

the real is no more than what it is. (Sami-Ali, 1980, 2002)

Erasing the non-real parts of reality has become a sort of imperative need. Or, at least, the exercise of putting them aside, classifying them as non-real and identifying to what kind of nonreality each one belongs.

Thus, it is understandable that the crucial obsession of our times has become separating the real from the unreal. Two very popular contemporary science fiction films, The Matrix (1999) and Inception (2010), show this very clearly. However, there is a notable difference between the two. The Wachowskis' The Matrix leads us to the most imperative choice between the unreal and the real, in which the former is passed over by the latter. Neo is given the choice of two pills - a red pill that will take him to the reality outside the Matrix, or the blue pill that will bring him back to the Matrix. Neo chooses the red pill, beginning his journey into a painful truth. Of course, his choice is determined by a Manicheistic fight between freedom and a real condition of slavery, reflecting a metaphysics that subjects human beings' meaning to a transcendent intentionality. In almost the opposite direction, Christopher Nolan's Inception refuses, at the end of the movie, to make that choice and clarify whether or not the reality experienced is the real itself or simply another dream. In a strong contrast with The Matrix's adversity to ambivalence, Inception is an extraordinary exhortation to an indecipherable ambivalence, keeping things exactly where they exist humanly.

According to Sami-Ali, the suppression of the imaginary is observable even in the way language is conceived. For him, the opposition between the literal and the figural is the opposition between the absence and presence of projection in the elaboration of experience of the world (Sami-Ali, 1983, 2002). And, even more incisively, the tendency towards literalness must be confronted with the problematic status of literalness in itself.

The banal brings into play a certain conception of language. It invites us to meditate on the fact that the two poles of discourse are not metaphor and metonymy, but, more generally, the literal and the figurative. That is why, in the Jakobsonian division of language, the very existence of the literal is problematic (...). (Sami-Ali, 1980, 2002)

The fact is that these tendencies towards the spread of the banal and literalisation are aspects, or even pre-conditions, of the very same "rule of neoliberal global contemporary reality" - the unlimited interchangeability and processuality of everything. Converting everything into banality and literalness is actually a device that produces the annihilation of the human subjectivity. As SamiAli asserts, "the banal object is one that can be produced and reproduced indefinitely, without any appeal to subjectivity." Ultimately, this definition of the banal applies to human beings themselves and to any means involved significantly in their existences.

\section{Bibliography}

Bauman, Z. (2007 [1993]). Modernidade e ambivalência. M. Penchel (trad.). Lisboa: Relógio d'Água.

Birken, L. (1999). Freud's "economic hypothesis": from Homo Oeconomicus to Homo Sexualis. American Imago, 56 (4): 311-330. 
Dick, P. K. (1996 [1968]). Do Androids Dream of Electric Sheep?. Del Rey/Ballantines Books.

Freud, S. (1919). The "uncanny" (Das Unheimliche) (URL: http://web.mit.edu/allanmc/www/fre ud1.pdf )

Freud, S. (s.d.). Civilisation and its Discontents (Unbehagen in der Kultur).

Haraway, D. (2000 [1983]). A cyborg manifesto. Science, technology and socialist-feminism in the late twentieth century. In D. Bell \& B. Kennedy, The cybercultures reader (pp. 291-324). Routlegde: London and New York.

Jentsch, E. A. (1906). On the psychology of the uncanny (Zur Psychologie des Unheimlichen). (Trans. by R. Sellars). URL: www.art3idea.psu.edu/locus/Jentsch_uncanny.pdf

Lacan, J. (1991). The Ethics of Psychoanalysis 1959-1960. Book.7 Seminar of Jacques Lacan by J.-A. Miller (ed.), D. Porter (trans.).

Lem, S. (1978 [1961]). Solaris (English trans.). NY: A Harvest book.

Lévinas, E. (1961). Totalité et infini: essai sur l'extériorité. M. Nijhoff.

Lyotard, J.-F. (1979). La Condition postmoderne. Rapport sur le savoir. Paris: Les éditions minuit.

Sami-Ali (2002 [1980]). O banal. (trad. A. M. P. Martins). Lisbon: Dinalivro.

Sartre, J.-P. (1985 [1960]). Critique de la raison dialectique. Paris: Gallimard.

\section{Filmography}

2001 - A Space Odyssey. Dir. Kubrik, Stanley. Metro-Goldwyn Mayer, 1968.

Blade Runner. Dir. Ridley Scott, Warner Bros., 1982.

Inception. Dir. Christopher Nolan, Warner Bros., 2010.

The Matrix. Dir. The Wachowskis, Warner Bros., 1999.

Solaris. Dir. Tarkovski, Andrei. Soviet Union, 1972.

Timbuktu. Dir. Abderrahmane Sissako, 2014. 